\title{
Homosexual Applicants to the Priesthood: How Many and Are They Psychologically Healthy?
}

\author{
Thomas G. Plante
}

Published online: 21 February 2007

(C) Springer Science+Business Media, LLC 2007

\begin{abstract}
The current investigation evaluated the psychological profiles of applicants to seminary who were identified as being either homosexual or heterosexual in orientation. The MMPI-2 from 63 seminary applicants conducted between 1990 and 2004 was reviewed. Results indicate that 49 applicants $(78 \%)$ identified themselves as being heterosexual while 14 applicants (22\%) identified themselves as being homosexual. Few psychological differences emerged on the MMPI-2 when comparing heterosexual to homosexual applicants.
\end{abstract}

Keywords Homosexuality $\cdot$ Priesthood $\cdot$ Seminary $\cdot$ Catholic church

A great deal of recent attention has focused on homosexual men in the priesthood. During the fall of 2005 much media attention centered on the release of Pope Benedict XVI's "instruction" (Congregation for Catholic Education, 2005) stating that homosexual men should not be allowed to enter seminary or be ordained as Roman Catholic priests. The instruction made clear that active homosexuals, those who experience "deep-seated homosexual tendencies," and those who support "gay culture" cannot be priests (p. 3). The instruction does not apply to priests already ordained.

While there are no official estimates of the number of homosexual men in the priesthood, best current estimates range from $10 \%$ to $60 \%$ (Cozzens, 2000) with most experts and authorities who have access to this information more closely estimating between $25 \%$ and 40\% (Plante, 2004, 2005; Sipe, 2004). Regardless of the most accurate figures, it is clear that there is a higher proportion of homosexual priests than homosexual men in the general population (Sipe, 2004) and that a substantial number of the 46,000 priests in the United States are indeed homosexual (Cozzens, 2000). If these estimates are even close to being accurate, eliminating all homosexual applicants to the priesthood would have enormous implications. Given the continuing decline in the number of men interested in becoming priests (Cozzens, 2000), eliminating all of the homosexual applicants to seminary would likely precipitate a

T. G. Plante $(\square)$

Psychology Department, Santa Clara University, Santa Clara, CA 95053, USA

e-mail: tplante@scu.edu 
major crisis in the Catholic Church. Eliminating approximately a quarter to a half of current and future applicants would have to have an enormous impact on the Church.

Many have wondered if the "crack down" on homosexuals in the priesthood is a response to the clergy sexual abuse crisis in the Catholic Church (Boston Globe Investigative Staff, 2002; Jenkins, 2001; Plante, 2005; Sipe 2004). Since $81 \%$ of the victims of priest child sexual abuse are boys (John Jay College of Criminal Justice, 2004), many have wondered if the clergy sexual abuse crisis might be best solved with the elimination of homosexual priests. However, many experts have also argued that homosexual orientation, by itself, is not a risk factor for sexual crimes against children (American Psychological Association, 1998). Furthermore, many have suggested that homosexual priests are often the scapegoat for the clergy sexual abuse problem (Plante, 2005). Sex-offending clergy frequently report that they victimize boys (even if they report being heterosexual) because boys are a victim of convenience (Plante, 2004). They often report that they have ready access to and trust with boys rather than girls.

The current study sought to determine how many applicants to religious life as priests are homosexual in orientation and to evaluate if they are similar to heterosexual applicants in terms of psychological functioning. Since there are so few research studies and empirical data available on this topic, there is a pressing need to determine at least some initial answers to these important questions. Since the recent Vatican instruction as well as other Vatican documents suggest that homosexuality is a disordered condition (Congregation for Catholic Education, 2005), it is important to determine if homosexual and heterosexual priest applicants differ in their psychological functioning. The current study used a convenience sample of 63 applicants to the priesthood who applied between 1990 and 2004 and thus applied prior to the Pope's recent instruction on homosexuality.

\section{Methods}

\section{Subjects}

Sixty-three applicants to the priesthood (mostly from one major Catholic religious order) were utilized as research participants (Mean age $=28.5, S D=7.7$, range $=17$ to 47 years). A total of 49 applicants identified themselves as being heterosexual $(78 \%)$ in orientation, while 14 identified themselves as being homosexual $(22 \%)$ in orientation. It is important to note that the sample is not necessarily representative of all priest applicants across the country and that applicants were carefully screened for a variety of characteristics before being approved for the psychological evaluation process. The current sample was also used in a previous published paper examining the overall psychological functioning of priest applicants (Plante, Aldridge, \& Louie, 2005). In that study, it was determined that applicants to the priesthood were generally well-adjusted as well as being socially responsible, interpersonally sensitive, and sociable as measured by the MMPI-2 (Hathaway \& McKinley, 1989).

\section{Measurements}

The MMPI-2 (Hathaway \& McKinley, 1989) is the most commonly used and researched psychological self-report measure available. It includes 567 true-false items that comprise 3 validity scales, 10 basic clinical scales, and over 50 supplementary and additional subscales. The most recent edition is normed on 1980 U.S. Census figures. The questionnaire is considered highly reliable and valid (Hathaway \& McKinley, 1989). 


\section{Procedure}

The applicants in the present study completed the MMPI-2 as well as a detailed clinical interview prior to admission to seminary between 1990 and 2004. Applicants were not referred for the interview and testing unless they satisfactorily met the many criteria the church formation and vocation staff sought. Sexual history and orientation were discussed during the interview session. The psychological evaluation was conducted as one of the last procedures of the application process prior to seminary admission. All MMPI-2 results were converted to standard scores and entered into a database by a research assistant using SPSS-X.

Results

Standardized $t$-scores from the applicants were compared to national norms using mean $t$-scores of 50 and standard deviations of 10 (Hathaway \& McKinley, 1989). Using independent $t$-tests on the MMPI-2 scores, significant differences between the homosexual and heterosexual groups emerged on the $M F$ (Masculinity-Femininity) scale, $t(60)=2.13$, $p<.05$, and the MA (Hypomania) scale, $t(60)=2.49, p<.05$, such that homosexual applicants scored higher on the $M F$ scale and lower on the $M A$ scale than heterosexual men. No significant differences emerged when examining any of the other clinical or validity measures (all $p^{6} \mathrm{~s}>.05$ ). However, the homosexual applicants were found to be older (average age $=32.4$ ) than the heterosexual applicants (average age $=27.5, t(60)=2.22$, $p<.05$ ). As of February 2005 (i.e., several months following the release of the Pope's instruction on homosexuality in the priesthood), 7 of the 14 homosexual priest applicants in this sample $(50 \%)$ remain in religious life as either priests or seminary students.

\section{Discussion}

Results from this investigation of 63 applicants to the priesthood suggest that the majority (78\%) report during a clinical interview that they are heterosexual in orientation while a sizable minority of $14(22 \%)$ report a homosexual orientation. In general, the psychological profiles of homosexual applicants do not differ from heterosexual applicants. However, homosexual applicants tended to score higher on the $M F$ scale and lower on the $M A$ scale than heterosexual applicants. Thus, these homosexual men had more gender-feminine interests than the heterosexual men but were less likely to be active, energetic, and outgoing than the heterosexual men. No differences emerged while examining the validity measures (e.g., lying, defensiveness) or any of the other clinical measures such as anxiety, depression, paranoia, social discomfort, and so forth. Half of the homosexual applicants remain in religious life as of February 2005.

A variety of methodological issues suggest that these results must be viewed with caution. First, this study utilized a modest number of applicants for religious life without the benefits of control groups or a representative national sample of priest applicants. Therefore, conclusions concerning the personality and psychological functioning of this group could be associated with a number of factors (e.g., education, social class, geographical location, screening process prior to the psychological evaluation), in addition to their desire to enter the priesthood in the particular Church groups that participated. Second, a number of analyses were conducted given the modest sample size which increases the chance of false-positive or Type I errors. All of the men completed psychological testing as part of the application procedure to enter the religious life. Therefore, they likely wanted to present a highly favorable 
view of themselves in the context of the application process. Finally, the information about sexual orientation was provided by the applicant during the clinical interview. It is possible that some applicants were not truthful in their disclosures.

Overall, results suggest that the number of men applying to religious life who are homosexual in orientation is significantly higher than in the general population of men and that these men are as well adjusted as and not significantly different in their psychological profiles from heterosexual men. Future research should utilize larger sample sizes and control conditions to better understand the psychological and personality functioning of clergy from various sexual orientations. During these challenging times for Catholic priests and the American Catholic Church in general, research is especially needed to assist both the Church and the general population in the hopes of developing better screening and selection measures for Catholic clergy. However, in the meantime, it appears that the answer to the question about the psychological health of homosexual applicants to the priesthood is yes, they are psychologically healthy and not very different from a psychological standpoint than heterosexual applicants.

\section{References}

American Psychological Association (1998). Answers to your questions about sexual orientation and homosexuality. Washington, DC: Author.

Boston Globe Investigative Staff. (2002). Betrayal: The crisis in the Catholic Church. New York: Little Brown.

Congregation for Catholic Education (2005). Concerning the criteria for the discernment of vocations with regard to persons with homosexual tendencies in view of their admission to the seminary and to holy orders. Vatican City: Author.

Cozzens, D. (2000). The changing face of the priesthood. Collegeville, MN: The Liturgical Press.

Hathaway, S. R., \& McKinley, J. C. (1989). Manual for the Minnesota Multiphasic Personality Inventory-2 ${ }^{\mathrm{TM}}$ $\left(M M P I-2^{\mathrm{TM}}\right)$. Minneapolis, MN: University of Minnesota Press.

Jenkins, P. (2001). Pedophiles and priests: Anatomy of a contemporary crisis. New York: Oxford.

John Jay College of Criminal Justice (2004). The nature and scope of the problem of sexual abuse of minors by Catholic priests and deacons in the United States. New York: Author.

Plante, T. G. (Ed). (2004). Sin against the innocents: Sexual abuse by priests and the role of the Catholic Church. Westport, CT: Greenwood.

Plante, T. G. (2005, October 26). On gay men in the priesthood: Scapegoating gays won't end clergy sex abuse. San Francisco Chronicle, B9.

Plante, T. G., Aldridge, A., \& Louie, C. (2005). Are successful applicants to the priesthood psychologically healthy? Pastoral Psychology, 54, 81-89.

Sipe, A. W. R. (2004). The crisis of sexual abuse and the celibate/sexual agenda of the Church. In T. G. Plante (Ed.), Sin against the innocents: Sexual abuse by priests and the role of the Catholic Church (pp. 61-72). Westport, CT: Greenwood. 